\title{
Pulmonary Venous Thrombosis and Cerebrovascular Accident in a Young Oral Contraceptive User Patient: A Case Report
}

\author{
Lai $\mathrm{IK}^{1}$, Buschle $\mathrm{MN}^{1}$, Grava $\mathrm{S}^{1^{*}}$ \\ ${ }^{1}$ Biological and Health Sciences Center, UniCesumar, PR, Brazil
}

Corresponding Author: Sergio Grava ORCID ID

Address: Biological and Health Sciences Center, UniCesumar, Av. Guedner 1610, Maringá, Paraná.

Received date: 24 November 2020; Accepted date: 21 December 2020; Published date: 29 December 2020

Citation: Lai IK, Buschle MN, Grava S. Pulmonary Venous Thrombosis and Cerebrovascular Accident in a Young Oral Contraceptive User Patient: A Case Report. Asp Biomed Clin Case Rep. 2020 Dec 29;4(1):6-10.

Copyright (C) 2021 Lai IK, Buschle MN, Grava S. This is an open-access article distributed under the Creative Commons Attribution License, which permits unrestricted use, distribution, and reproduction in any medium provided the original work is properly cited.

\begin{abstract}
Since there are millions of pill users around the world, the relationship between oral contraceptives, thrombotic events, and the cerebrovascular accident has been the focus of numerous studies. Most of the cases described in the literature are of deep venous thrombosis in the lower limbs and thromboembolism in the pulmonary artery. This article aims to report a rare case of pulmonary vein thrombosis, along with cerebrovascular accident in a young patient who uses oral contraceptives. We seek to elucidate this relationship between the use of different oral contraceptives and the risk of thrombus formation, in addition to providing a brief review of these pathological episodes in the body. In view of the scarce existence of studies with reports of pulmonary venous thrombosis, it is expected to provide information to the entire medical community.
\end{abstract}

\section{Keywords}

Venous Thrombosis, Oral Contraceptives, Pulmonary Embolism, Stroke, Pulmonary Thromboembolism

\begin{abstract}
Abbreviations
OC: Oral Contraceptives; CVA: Cerebrovascular Accident; VTE: Venous ThromboEmbolism; WHO: World Health Organization; DVT: Deep Vein Thrombosis; PTE: Pulmonary ThromboEmbolism; CVAi: Ischemic Cerebrovascular Accident; ICU: Intensive Care Unit; ASA: AcetylSalicylic Acid; MRI: Magnetic Resonance Imaging; CT: Computed Tomography; LMCA: Left Medium Cerebral Artery; CTA: CT Angiography; EE: Ethinyl Estradiol; APC: Activated Protein C; EMA: European Medicines Agency; PRAC: Pharmacovigilance Risk Assessment Committee
\end{abstract}

\section{Introduction}

The relationship between oral contraceptives (OC), thrombotic events, and cerebrovascular accident (CVA) has been the focus of numerous studies since approximately 100,000,000 women worldwide use pills. Of that number, $27 \%$ of reproductive age women in Brazil use OC [1]. A study indicated that venous thromboembolism (VTE), including deep vein thrombosis and pulmonary embolism in non-OC users, affects per year about 4-5 out of 10,000 women, increasing to 9-10 cases when there is the use of OC [2]. In regards to CVA, 14 studies demonstrated that the use of OC increases the risk of this event, considered by the World Health Organization (WHO) a complication in primary care. Smoking, arterial hypertension, hypercholesterolemia, obesity, alcohol, migraine, and personal and family history of thrombotic diseases, are also factors implied in the increase of CVA incidence [3]. 
Citation: Lai IK, Buschle MN, Grava S. Pulmonary Venous Thrombosis and Cerebrovascular Accident in a Young Oral Contraceptive User Patient: A Case Report. Asp Biomed Clin Case Rep. 2020 Dec 29;4(1):6-10.

Venous thromboembolism is commonly represented by deep vein thrombosis (DVT), which affects mainly veins in the lower limbs. Pulmonary thromboembolism (PTE), in almost $100 \%$ of cases, affects the pulmonary artery, and cases in which the pulmonary vein is affected are rare. The incidence of VTE in the global population is 1-2 cases per 1000 individuals per year, while in people over 85 years old it increases to 8 cases per 1000 individuals per year [4].

The incidence of CVA has being presenting a decline in developed countries, but in low and middle-income countries it continues to increase, corresponding to $85 \%$ of the global cerebrovascular accident load [5]. A worrying factor is that, according to The Lancet Journal [6], the global prevalence in adults aged 20 64 years increased by $25 \%$ between 2010 and 2014 .

\section{Case Presentation}

We report the case of a female patient, 34 years old, white, doctor, previously healthy, whose only risk factor was the use of oral contraceptives composed of ethinylestradiol + cyproterone acetate. The patient presented headache on the previous night and, two hours before hospital admission, she started with sudden dysarthria and right hemiplegia, with no personal/family history of VTE or ischemic cerebrovascular accident (CVAi). At the physical exam, she was flushed, hydrated, oriented in time and space, isophoto reactive pupils; the physical examinations: respiratory, cardiac, and abdominal indicated normal conditions. There were no alterations in the lower limbs that could suggest DVT.

Due to the suggestive picture of CVA, the patient was admitted to the Intensive Care Unit (ICU), administrated with a full dose of Enoxaparin, loading doses of Clopidogrel and acetylsalicylic acid (ASA). She was also submitted to laboratory and imaging exams, such as magnetic resonance imaging (MRI), computed tomography (CT) of the skull, and Angio-CT, in which were found hyperdense injuries and filling failures in the left medium cerebral artery (LMCA) territory (Fig1A and Fig-1B).

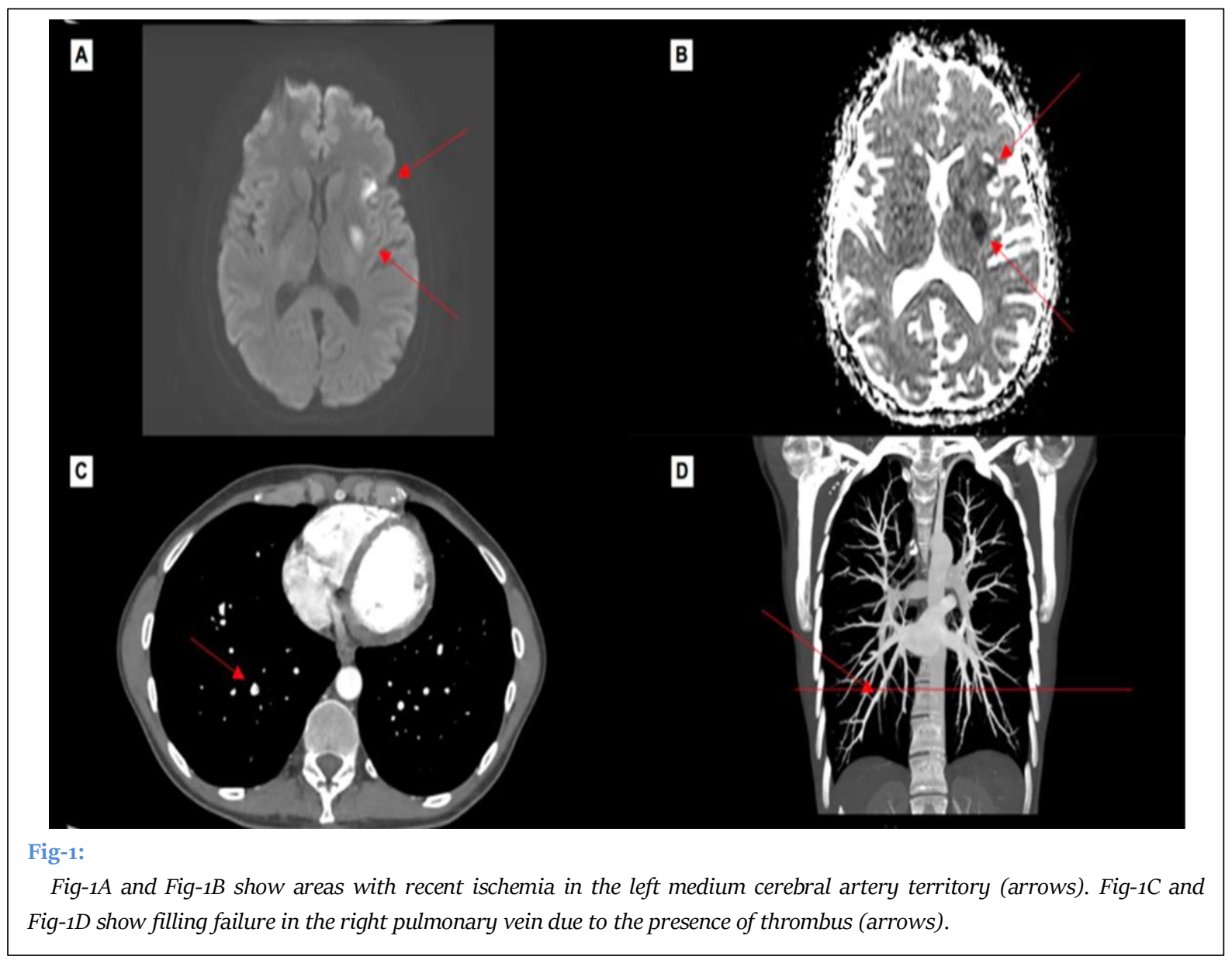


During the diagnostic investigation, chest CT angiography (CTA) was performed, showing thromboembolism in pulmonary veins of the right lower lobe, and no thrombi was found in the pulmonary arteries and their segmentation (Fig-1C and Fig-1D). Sequentially, full anticoagulation was maintained with Enoxaparin and Warfarin, and the use of ASA and Simvastatin was also maintained. There was a good evolution and the patient recovered completely, with no sequels.

\section{Discussion}

Originally, the suspicion of the reported case was CVAi, because the clinical picture presented at hospital admission - later confirmed by MRI - showed areas of ischemia in LMCA territory (Fig-1A and Fig-1B). During the investigation of the possible etiology, chest CTA revealed a filling failure in the right lower lobe's pulmonary vein due to the presence of thrombus and absence of changes in pulmonary arteries and its segmentations (Fig-1C and Fig-1D). Therefore, the overview presented suggests a rare case of pulmonary venous thrombosis.

As a result of this event, the formation or - more commonly - the migration of thrombi from the cardiac cavities to brain vessels may occur, occluding, and thus triggering an ischemic CVA, as reported in the case above. It is believed, therefore, that in this case, the CVA etiology was the formation of a thrombus in the pulmonary vein, which moved to the left atrium and ventricle, aortic artery, internal carotid artery, and LMCA, thus suffering occlusion and, consequently, ischemia in its territory.

Among the risk factors of this pathology, the only one presented by the patient was the use of oral contraceptives, composed of Ethinyl estradiol 0.035 $\mathrm{mg}$ and cyproterone acetate $2.0 \mathrm{mg}$, which is related to greater changes in coagulation components and the consequent increase of thromboembolic events [7].

Venous thromboembolism is a pathological process triggered by the alteration of coagulation components and, consequently, partial or total obstruction of vessels by an aggregate of fibrin and platelets.
It is explained by three factors: blood stasis, hypercoagulability, and endothelial injury, known as Virchow's Triad [1]. The thrombus formed in deep veins of the lower limbs can migrate to the right heart cavities and then pulmonary arteries, thus not being possible to cause a CVA [4].

OCs are composed of synthetic hormones, such as estrogen and progesterone, which can be used isolated (progestogens) or in combination. The combinations are classified as: $1^{\text {st }}$ generation - OC with Ethinyl estradiol (EE) combined with medroxyprogesterone; $2^{\text {nd }}$ generation - EE combined with levonorgestrel; $3^{\text {rd }}$ generation - EE combined with gestodene, norgestimate or desogestrel; $4^{\text {th }}$ generation - EE combined with drospirenone and OC not classified as generations: cyproterone acetate $[1,8]$.

Estrogen, notably Ethinyl estradiol, may cause important alterations in the hemostatic system, such as the $30-50 \%$ increase in the activity of procoagulant factors (factors II, VII, VIII, IX, X, XI, XII, XIII, and fibrinogen) [9], the reduction of natural anticoagulant factors (C-reactive protein, protein S, antithrombin) and the stimulation of endothelial dysfunction, which results in thromboembolic events such as DVT, PTE and CVA [1-3,9]. In addition to these hemostatic changes, those combined with higher doses of Ethinyl estradiol, such as the OC used by the patient, develop greater resistance to activated protein C (APC), higher levels of D-dimer, and changes in the lipid profile, such as increased LDL and total cholesterol $[8,9]$.

Initially, it was believed that only the estrogen dose was related to thromboembolic events. However, in 1995, it was discovered that combined OCs containing desogestrel, gestodene, or norgestimate are related to a higher risk of VTE in comparison to those combined with levonorgestrel or norgestrel [10]. It is estimated that the $3^{\text {rd }}$ and $4^{\text {th }}$ generation combinations increase this risk by 9-12 times, while the $2^{\text {nd }}$ generation ones increase by 5-7 times [11].

According to the European Medicines Agency (EMA)'s Pharmacovigilance Risk Assessment Committee (PRAC), those combined with EE and 
cyproterone acetate represent a risk similar to those of the $3^{\text {rd }}$ generation, this being the composition of the contraceptive used by the patient [7]. This increased risk is directly related to the high affinity of progestogens both for their own receptors and for other steroid receptors, such as mineralocorticoids, estrogens, glucocorticoids, and especially androgens [9]. Thus, we can conclude that $3^{\text {rd }}$ generation progestogens and cyproterone acetate present this risk increased by the lower androgenic action and strong antiandrogenic action, respectively [10].

\section{Conclusions}

We have reported the investigation of a cerebrovascular accident with cause attributed to a rare case of thrombosis in the pulmonary vein, in which the patient did not present chronic diseases, risk factors, and coagulopathies, personal or family history that could be associated with the formation of thrombotic events. Thus, it can be concluded that the cause of the thrombogenic process may have been the continuous use of an oral contraceptive with high antiandrogenic potential.

\section{Acknowledgments}

We thank Hospital Paraná de Maringá and the patient for allowing the study of this case. We also thank all of those who have contributed direct or indirectly to the development of this work.

\section{Funding Information}

This work has not been funded by any institution or organization.

\section{Conflict of Interests}

All authors have read and approved the final version of the manuscript. The authors have no conflicts of interest to declare.

\section{References}

[1] Sousa ICA, Álvares ACM. A trombose venosa profunda como reação adversa do uso contínuo de anticoncepcionais orais [Deep venous thrombosis as an adverse reaction of continuous use of oral contraceptives]. Rev Cient Sena Aires. 2018;7(1):54-65. Portuguese.

[2] Federação Brasileira das Associações de Ginecologia e Obstetrícia. Tromboembolismo venoso e contraceptivos hormonais combinados. São Paulo: Febrasgo; 2016. Available from:

https://www.febrasgo.org.br/media/k2/attachments/ 04-

TROMBOEMBOLISMO_VENOSO_E_CONTRACEPTIVO S_HORMONAIS_COMBINADOS.pdf

[3] Lima ACS, Martins LCG, Lopes MVO, Araújo TL, Lima FET, Aquino PS, Moura ERF. Influence of hormonal contraceptives and the occurrence of stroke: integrative review. Rev Bras Enferm. 2017 MayJun;70(3):647-55. English, Portuguese. [PMID: 28562816]

[4] Phillippe HM. Overview of venous thromboembolism. Am J Manag Care. 2017 Dec;23(20 Suppl):S376-82. [PMID: 2929766o]

[5] Esenwa C, Gutierrez J. Secondary stroke prevention: challenges and solutions. Vasc Health Risk Manag. 2015 Aug 7;11:437-50. [PMID: 26300647]

[6] Giroud M, Jacquin A, Béjot Y. The worldwide landscape of stroke in the 21st century. Lancet. 2014 Jan 18;383(9913):195-97. Erratum in: Lancet. 2014 Feb 22;383(9918):696. [PMID: 24449941]

[7] Ferreira LF, D’Ávila AMFCO, Safatle GCB. Uso da pílula anticoncepcional e as alterações das principais vias metabólicas [The use of contraceptive pill and alterations of main metabolic pathways]. Femina. 2019;47(7):426-32. Portuguese.

[8] Silva JE, Santana KS, Nunes JS, Santos JC, Terra Júnior AT. A relação entre o uso de anticoncepcionais orais e a ocorrência de trombose. Rev Cient Fac Educ e Meio Ambiente. 2018;9(1):38398. Portuguese

[9] Brito MB, Nobre F, Vieira CS. Hormonal contraception and cardiovascular system. Arq Bras Cardiol. 2011 Apr;96(4):e81-89. English, Portuguese, Spanish. [PMID: 21359483]

[10] Davis KH, Asiimwe A, Zografos LJ, McSorley DJ, Andrews EB. Evaluation of Risk-Minimization Activities for Cyproterone Acetate $2 \mathrm{mg}$ /Ethinylestradiol $35 \mu \mathrm{g}$ : A Cross-Sectional Physician Survey. Pharmaceut Med. 2017;31(5):339-51. [PMID: 29056853] 
Citation: Lai IK, Buschle MN, Grava S. Pulmonary Venous Thrombosis and Cerebrovascular Accident in a Young Oral Contraceptive User Patient: A Case Report. Asp Biomed Clin Case Rep. 2020 Dec 29;4(1):6-10.

[11] Klok FA, Barco S. Optimal management of hormonal contraceptives after an episode of venous thromboembolism. Thromb Res. 2019 Sep;181 Suppl 1:S1-S5. [PMID: 31477219] 